\title{
POLARIZED LIGHT: A CONSERVATIVE THERAPEUTIC APPROACH TO CHRONIC HAND ECZEMA
}

\author{
Hany M. I. Elgohary ${ }^{* 1}$, Hadaya M. R. Eladl ${ }^{1}$, Ibrahim E. Abdelzaher ${ }^{2}$. \\ *1 Department of Physical Therapy for Surgery ,Faculty of Physical Therapy, Cairo University, \\ El-Tahrir st. Dokki - Giza, P.O.Box 11432, Egypt. Tel: 00201001344332 \\ 2 Department of Physical Therapy and Health Rehabilitation, College of Applied Medical \\ Sciences, Aljouf University, Sakaka, P.O. 2014, Kingdom of Saudi Arabia. Tel: 00966590997821
}

\section{ABSTRACT}

Background and aim: the use of polarized light as conservative noninvasive treatment for wounds and skin diseases has been grown and spread in the medical field because of its benefits to overcome inflammatory conditions with no side effects or hazards. The aim of study was to evaluate the efficiency of polarized light in the treatment of chronic hand eczema as conservative treatment.

Subjects: Fifty participants of ( 28 males $\& 22$ females) with chronic hand eczema affecting palmar or dorsal hands enrolled randomly into two equal groups; experimental group received polarized light 6 sessions per week for 6 successive weeks and topical Calcipotriol (Daivonex) in the morning and Clobetasol (Dermovate) in the evening while control group received sham polarized light and topical Calcipotriol (Daivonex) in the morning and Clobetasol (Dermovate) in the evening for the same period of time. Intensity, extent of disease and skin thickness were measured before and after the treatment by hand eczema severity index and ultrasonography respectively.

Results: the results of this study revealed that there were significant differences between both groups of the study in favor of the experimental group regarding results after the treatment protocol.

Conclusion: polarized light has a potential effect in decreasing skin thickness, intensity and extent of chronic hand eczema after 6 weeks of treatment.

KEY WORDS: Polarized light, Chronic hand eczema, Skin thickness.

Address for correspondence: Dr. Hany M. I. Elgohary PhD PT, Department of Physical Therapy for Surgery ,Faculty of Physical Therapy, Cairo University, El-Tahrir st. Dokki - Giza, Giza, P.O.Box 11432, Egypt.Tel:00201001344332,E-Mail: gohary75pt@hotmail.com

\section{Access this Article online}

Quick Response code

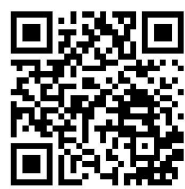

DOI: $10.16965 /$ ijpr.2017.154
International Journal of Physiotherapy and Research

ISSN 2321- 1822

www.ijmhr.org/ijpr.html

Received: 07-04-2017

Peer Review: 07-04-2017

Accepted: 24-04-2017

Revised: None
Published (O): 11-06-2017

Published (P): 11-06-2017

\section{INTRODUCTION}

There is increasing evidences that hand eczema (HE) is highly prevalent skin disturbance influencing the hands. HE is not a uniform disease as it varies in etiology, morphology, and severity which make its diagnosis a challenging medical decision. Furthermore, there are several treatment alternatives for the condition in case of failure of the topical corticosteroids to alleviate the HE symptoms [1]. Chronic hand eczema not only lays a large strain on patients, usually affecting their capacity to accomplish work but also has an impact on quality of life as well [2]. Moreover, the treatment costs are being highly associated with the correspondence to work [3]. The risk factors affecting dermatitis 
include the use of latex gloves, chemical vulnerability, and repeated hand washing therefore, health care specialists, machinists, housewives, and beauticians are part of individuals who are at a tremendous risk for developing manifestations [4]. Other forbidden factors include a history of childhood eczema and female sex [5]. Despite use of topical therapy is sufficient for various patients, some require supplementary systemic medications [6]. These medications have a potential for severe side effects, such as liver toxicity and renal toxicity (methotrexate, cyclosporine) teratogenicity (oral retinoids and skin melanoma) [7]. Which restrict their long-term effectiveness [8].

The Bioptron Light Therapy (BLT) is a common restricted light treatment method with an emitting light that is related to the element of the electromagnetic waves generated directly by the sun without serious UV radiation. BLT devices emit light including a span of wavelengths that match the visible light in addition to infrared radiation, both of which have been stated to animate the physiological response [9]. Furthermore, BLT can improve skin healing and lessen the embarrassment correlated with different skin dysfunctions. Additionally, BLT has biostimulative outcomes if administered to the skin, it enhances light-sensitive intracellular compositions and biomolecules [10].

This launches cellular chain responses and triggers what so-called secondary responses, which are not only confined to the treated skin area nevertheless; it can affect the entire body. The mechanisms of action are not quite clear, despite being revealed in terms of photobiomodulation [11, 12]. The literatures review revealed biom-odulation as the manner of altering the routine biochemical response of a cell or tissue within the usual range of its role to excite the cell's intrinsic metabolic potential to react to a stimulus $[13,14]$. When biomodulation befall from a photon shifting its response to a chromophore, it is sarcastic too as photobio modulation $[15,16]$.

Despite there are fewer reports regarding the clinical impact of polarized light on chronic hand eczema, the current study was conducted to estimate the potency of linear polychromatic non-coherent light (Bioptron light) in the treat ment of chronic hand eczema.

\section{MATERIALS AND METHODS}

All patients from the department of dermatology, Mansoura University Hospitals over a period of 6 months who had been diagnosed as chronic hand eczema of both palmer and dorsal aspects were invited to participate in this study. They were diagnosed by the department staff members based on clinical and physical examination tools using both ultrasonography measurement for the skin thickness and the Hand Eczema Severity Index (HECSI) by Held et al with permission [17]. Only fifty patients ( 28 males \& 22 females) met our inclusion criteria joined the study; those with ages ranged from 25 to 55 years and had chronic hand eczema, participants enrolled in the study. The hospital ethics committee approved the conduction of the study; each participant assigned a given consent in Arabic form prior to participate in this study. Those who had history of phototherapy intolerance, skin malignancy, acute infection of the treatment area, pregnant women, diabetic, sensory disorders, circulatory insufficiency or if they received radiotherapy of the area to be treated in the last six months were excluded from the study. Participants were randomly assigned into two groups of equal number. Group A (experimental) received polarized light 6 sessions per week for 6 successive weeks and topical Calcipotriol (Daivonex) in the morning and Clobetasol (Dermovate) in the evening. Group $B$ (control) received sham polarized light and topical Calcipotriol (Daivonex) in the morning and Clobetasol (Dermovate) in the evening for the same period of time.

Procedure of the study: Patients were guided solely or in a group toward the preparation, processing and the benefits of the study. The procedures of the study were divided into two main categories.

\section{Measurement procedures:}

Measurement of Skin Thickness: $7.5 \mathrm{MHz}$ Ultrasonography was used to measure the skin thickness related to eczema changes [18].

Measurements were done before starting the treatment protocol and after 6 weeks for both groups of the study. Ultrasonography measure 
ments were performed by the same investigator throughout the entire procedures. The palmer or the dorsal aspects of the hand were investigated in relation to another fixed land mark. Participants were allowed to be adapted to the examination room through giving them a time of 10 minutes of rest. Ultrasound gel as a coupling medium was used and adjusted to be $1 \mathrm{~mm}$ to ensure efficiency. The printed paper from the device describes the thickness of the skin $[19,20]$.

Determination of the severity of hand eczema: The hand is divided into 5 regions which are: the tips of the fingers, the fingers from the finger tips down to the knuckles, the palm, the dorsal aspect of the hand, and the wrist. In each region, the affected area was given a score from 0 to $4(0.0 \% ; 1,1-25 \% ; 2,26$ $50 \% ; 3,51-75 \%$, and $4,76-100 \%)$ for the extent of clinical symptoms.

Calculation of the intensity: For each of the five areas of the hand that were mentioned previously, the intensity of the followings six clinical signs: Erythema, Induration/ Papulation, Vesicles, Fissuring, Scaling and Edema was graded on the following scale: 0 , no skin changes; 1, mild cases; 2 , moderate and 3, Severe.

Estimation of the total sore: The score given for the extent at each location was multiplied by the intensity of each clinical feature, and the total sum called the HECSI score was calculated, varying from 0 to a maximum severity score of 360 points.

Treatment procedures: Each participant in the experimental group was placed in a comfortable relaxed position then polarized light device was applied for eight minutes, in a perpendicular manner at a distance of $10 \mathrm{~cm}$. from the level of the hand, six times a week for six successive weeks in addition to the topical Calcipotriol (Daivonex) in the morning and Clobetasol (Dermovate) in the evening. While the control group received sham polarized light for eight minutes per session, six times a week for six successive weeks in addition to topical Calcipotriol (Daivonex) in the morning and Clobetasol (Dermovate) in the evening.

Statistical Analysis: The mean, the standard deviation for age, duration of the disease were used as a primary source of connecting facts about each parameter to measure central tendency.

Paired t-test was used to compare variables within each group to detect level of significance. The results was considered as statistically significant If the $P$ - value was less than or equal to 0.05 , while unpaired t-test was used to compare the variables between groups to detect their level of significance. Both paired and unpaired t test were conducted through graph pad software version 6.

Table 1: Demographic and Baseline Characteristics of Age and Duration of the Disease.

\begin{tabular}{|c|c|c|c|c|c|}
\hline Variable & Group & Mean \pm SD & Minimum & Maximum & P-Value \\
\hline \multirow{2}{*}{ Age / year } & Group A & $41.2 \pm 8.86$ & 25 & 53 & \multirow{2}{*}{$0.1906^{*}$} \\
\cline { 2 - 6 } & Group B & $37.56 \pm 10.46$ & 26 & 56 & \\
\hline \multirow{2}{*}{ Duration/ month } & Group A & $31.6 \pm 12.46$ & 13 & 58 & \multirow{2}{*}{$0.7479^{*}$} \\
\cline { 2 - 5 } & Group B & $30.32 \pm 15.39$ & 12 & 56 & \\
\hline
\end{tabular}

*non-significant

Table 2: Baseline Percentages of Gender and Location of the Disease.

\begin{tabular}{|c|c|c|c|}
\hline \multicolumn{2}{|c|}{ variable } & Group A & Group B \\
\hline \multirow{2}{*}{ sex } & Male & $13(52 \%)$ & $14(56 \%)$ \\
\cline { 2 - 4 } & female & $12(48 \%)$ & $11(44 \%)$ \\
\hline \multirow{2}{*}{ Location } & palmer & $15(60 \%)$ & $11(44 \%)$ \\
\cline { 2 - 4 } & Dorsal & $10(40 \%)$ & $14(56 \%)$ \\
\hline
\end{tabular}

Table 3: Statistical Analysis of Skin Thickness and HECSI Before and After the Treatment within Both Groups.

\begin{tabular}{|c|c|c|c|c|}
\hline \multirow{2}{*}{ Variable } & \multirow{2}{*}{ Group } & \multicolumn{2}{|c|}{ Mean \pm SD } & \multirow{2}{*}{ P- value } \\
\cline { 3 - 4 } & & Pre & Post & \\
\hline \multirow{2}{*}{ Skin thickness } & Group A & $19.72 \pm 3.09$ & $6.64 \pm 1.63$ & $0.0001^{* * *}$ \\
\cline { 2 - 5 } & Group B & $18.92 \pm 3.30$ & $15.40 \pm 3.12$ & $0.0001^{* * *}$ \\
\hline \multirow{2}{*}{$\begin{array}{c}\text { Hand Eczema Severity } \\
\text { Index(HECSI) }\end{array}$} & Group A & $95.32 \pm 6.22$ & $66.00 \pm 9.70$ & $0.0001^{* * *}$ \\
\cline { 2 - 5 } & Group B & $93.28 \pm 8.86$ & $89.64 \pm 9.04$ & $0.0029 * *$ \\
\hline
\end{tabular}

Table 4: Statistical Analysis of Skin Thickness and HECSI after the Treatment between Both Groups.

\begin{tabular}{|c|c|c|c|}
\hline variable & Group A (post) & Group B (post) & P-value \\
\hline Skin thickness & $6.64 \pm 1.63$ & $15.40 \pm 3.12$ & $0.0001^{* * *}$ \\
\hline $\begin{array}{l}\text { Hand Eczema } \\
\text { Severity Index }\end{array}$ & $66.00 \pm 9.70$ & $89.64 \pm 9.04$ & $0.0001^{* * *}$ \\
\hline
\end{tabular}

$* * *$ highly significant

Table 1: represents the demographic and baseline characteristics of both age and duration of the disease for both groups of the study before starting the treatment protocol, which shows that there were no significant differences between both groups that revealed the proper matching between groups. 
Table 2: represents baseline percentages of both gender and location of the disease that revealed engaging both sexes in the study as well as choosing both Palmar and dorsal aspects of the hands.

Table 3: showed significant differences within both experimental and control groups as regard to skin thickness and hand eczema severity index and thickness of skin.

Table 4: showed significant differences between experimental and control groups as regard to skin thickness and hand eczema severity index as $p$ value $=0.001$.

\section{DISCUSSION}

Light therapy has been used for a long time to treat inflammatory processes and skin diseases. Moreover several studies were conducted in this field to find out the underlying theories and mechanisms of action of light therapy. Furthermore, scientists exerted huge efforts to invent new treatment equipment that introduce alternative non-traditional solutions and contribute to better treatment for the debilitating problems of the skin. One of these advances is the use of BLT devices either at homes or through a well trained professional.

Our aim of the current study was to investigate the apparent role of light therapy in treating a difficult notorious problem such as chronic hand eczema that affect a variety of patients worldwide, as well as to use some of the nearly natural noninvasive tool as complementary aids.

Participants of this study were allocated randomly into two equal groups; Experimental group that received BLT in addition to topical Calcipotriol (Daivonex) in the morning and Clobetasol (Dermovate) in the evening while the control group received sham BLT in addition to topical Calcipotriol (Daivonex) in the morning and Clobetasol (Dermovate) in the evening. Despite of limited number of participants, all effort and precautions were done to assure restricted measures of single blind experiment bases throughout the entire study procedures by holding all information that could affect our results from all participants in both groups. UItrasonography was used to measure the skin thickness before and after six weeks from the beginning of the treatment protocol for both groups, while hand eczema severity index was used to calculate the intensity and the extent of the disease before starting the treatment and after six weeks from the beginning of the treatment.

The results of the current study showed that there were non-significant difference between both groups regarding pre- treatment data of both skin thickness and the hand eczema severity index that reflects the proper matching between both groups, while there were significant reduction in both skin thickness and hand eczema intensity and extent when comparing between both groups after the treatment procedure in favor of the experimental group as shown in tables 3 and 4 in addition to figures 1 and 2.

Fig. 1: Skin thickness for both groups before and after the treatment.

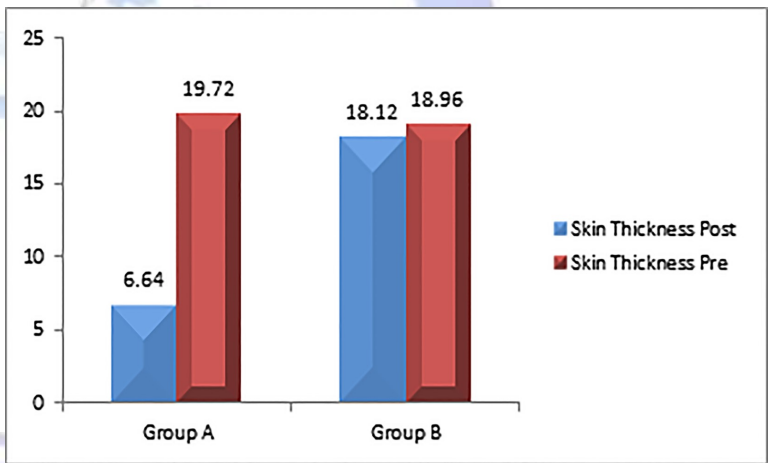

Fig. 2: Hand Eczema Severity Index (HECSI) for Both Groups before and After the Treatment.

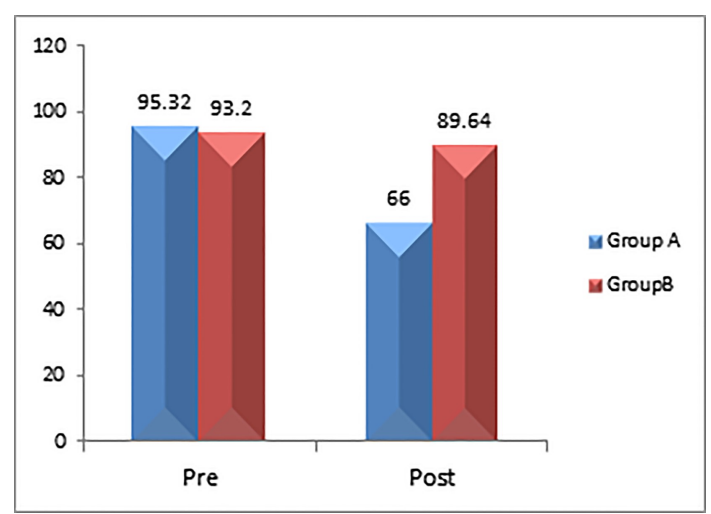

Although, there is a lack of literature regarding the exact effect of BLT in the treatment of skin diseases, It affects efficiently in the management of those kinds of diseases through its antiinflammatory effect, decreasing the high proinflammatory cytokines such as TNF-á, IFN-ã, and IL-2 [16]. It enhances and modifies the tissue repair and regeneration processes as well 
as the activation of the human defense-mechanisms as it acts to support the regenerative abilities of the body and so, helps the body to generate its own healing capabilities [21].

Likewise, some researchers concluded that the mechanism of light therapy may be explained in terms of photobiomodulation [22].

Biomodulation is the means of changing the actual biochemical response of a cell or tissue within the normal range of its function to stimulate the cell's natural metabolic potential to react to a motive [23]. Furthermore contemporary studies revealed that photobiomodulation could control the inflammatory responses and improve inevitable healing, too [24].

In a study of using polarized light in the treatment of acrodermatitis continua, 4 times the clinical exposure of LPPL with topical steroid application displayed clinical advance and the impact was maintained for several months without demand for further topical steroid utilization. It was assumed in this study that polarized light could act favorably on the inflammatory skin conditions without any side effects [9]. Eventually, BLT may help to treat skin ailments such as atopic dermatitis through relieving pain as well as inflammation, via promoting a healing response in the skin [25].

This study was limited to variances of the patients and their reactive effects on the rate of recovery and to some social aspects especially with females. Further researches should be undertaken to use other objective assessment methods to measure the severity and extent of chronic hand eczema. Also, further researches should be undertaken to include large number of subjects providing better statistical analysis of data.

\section{CONCLUSION}

This study concluded that light therapy has a likely advantage in the management of chronic hand eczema. The hand eczema severity index and the skin thickness were significantly reduced after 6 weeks of light therapy treatment combined with topical medications more than sham polarized light and topical medications.

\section{ACKNOWLEDGEMENTS}

We dispense gratitude to all the participants who were engaged to the study for their kind attitude and allegiance to accomplish this work.

\section{Conflicts of interest: None}

\section{REFERENCES}

[1]. Bissonnette R, Diepgen TL, Elsner P, English J, Graham-Brown R, Homey B, Luger T, Lynde $C$, Maares J, Maibach HI.Redefining treatment options in chronic hand eczema (CHE). Journal of European Academy of Dermatoylogy and Venerology 2010;24:1-20.

[2]. Fowler JF, Ghosh A, Sung J, Emani S, Chang J, Den E, Thorn D, Person J, Duh MS. Impact of chronic hand dermatitis on quality of life, work productivity, activity impairment, and medical costs. Journal of the American Academy of Dermatology. 2006; HYPERLINK http://www.sciencedirect.com/ science?_ob=PublicationURL\&_tockey=\%23TOC\%236928\%23 2006\%23999459996\%23616990\%23FLA\%23\&_c di $=6928 \&$ \& pubType $=J \& v i e w=c \&$ \&uth $=y \&$ _a $c c t=C 000050221 \&$ _version $=1 \&$ _urlVersion $=$ 0\&_userid=10\&md5=08b63926b423579436090 549322420154 $: 448-457$.

[3]. Charan UP, Peter CV, Pulimood SA. Impact of hand eczema severity on quality of life. Indian Dermatology Online Journal. 2013;4:102-105.

[4]. Lampel HP, Patel N, Boyse K, O’Brien SH, Zirwas MJ. Prevalence of hand dermatitis in inpatient nurses at a United States hospital. Dermatitis. 2007; 18: 140-142.

[5]. Perry AD, Trafeli JP. Hand Dermatitis: Review of Etiology, Diagnosis, and Treatment. Journal of American Board of Family Medicine. 2009;22:325-330.

[6]. Paulden M, Rodgers M, Griffin S, Slack R, Duffy $S$, Ingram JR, Woolacott N, Sculpher M. Alitretinoin for the treatment of severe chronic hand eczema. Health Technology Assessment. 2009;14:39-46.

[7]. Lim JL, Stern RS. High levels of ultraviolet B exposure increase the risk of non-melanoma skin cancer in psoralen and ultraviolet A-treated patients. Journal of Investigative Dermatology. 2005;124:505513.

[8]. Stern RS The risk of melanoma in association with long-term exposure to PUVA. Journal of the American Academy of Dermatology. 2001;44:755-761.

[9]. Choi M, Na SY, Cho S, Lee JH. Low Level Light Could Work on Skin Inflammatory Disease: A Case Report on Refractory Acrodermatitis Continua. Journal Korean Medicine Science. 2011;26:454-456.

[10]. Medenica L, and Lens M. The use of polarized polychromatic non coherent light alone as a therapy for venous leg ulceration. Journal of wound care. 2003;12:37-40.

[11]. Duroviæ A, Mariæ D, Brdareski Z, Jevtiæ $M$, Durdeviæ $S$. The effects of polarized light therapy in pressure ulcer healing, Vojnosanitetski Pregled. 2008;65:906-912.

[12]. Monstrey S, Hoeksema H, Depuydt K, Van Maele G Van Landuyt K, Blondeel P. The effect of polarized 
light on wound healing. European Journal of Plastic Surgery. 2002;24:377-382.

[13].Beissert S and Schwarz T. Role of immunomodulation in diseases responsive to phototherapy. Methods. 2002;28:138-144.

[14]. Colic M, Vidojkovic N, Jovanovic M, Lazovic G. The use of polarized light in aesthetic surgery. Aesthetic Plastic Surgery. 2004;28:324-27.

[15]. Young S, Bolton P, Dyson M, Harvey W, Diamanto poulos C. Macrophage responsiveness to light therapy. Lasers Surgery and Medicine. 1989;9:497505.

[16]. Zhevago NA, Samoilova KA. Pro- and anti-inflammatory cytokine content in human peripheral blood after its transcutaneous (in vivo) and direct (in vitro) irradiation with polychromatic visible and infrared light. Photomedicine and Laser Surgery. 2006;24:129-139.

[17]. Held E, Skoet R, Johansen JD, Agner T. The hand eczema severity index (HECSI): a scoring system for clinical assessment of hand eczema. A study of inter- and intra-observer reliability. British Journal of Dermatology. 2005;152:302-307.

[18].Jasaitiene $D$, Valiukeviciene $S$, Linkeviciute G, Raisutis R, Jasiuniene E, Kazys R. Principles of high-frequency ultrasonography for investigation of skin pathology. Journal of the European Academy of Dermatology and Venereology. 2011;25:375382.

[19].Polañska A, Silny W, Jenerowicz D, Knio ${ }^{3} a$ K, Moliñska-Glura M, Dañczak-Pazdrowska A. Monitoring of therapy in atopic dermatitis-observations with the use of high-frequency ultrasonography. Skin Research and Technology. 2015;21:35-40.
[20]. Chami L, Lassau N, Chebil M, Robert C. Imaging of melanoma: usefulness of ultrasonography before and after contrast injection for diagnosis and early evaluation of treatment. Clinical, Cosmetics and Investigational Dermatology. 2011;14:1-6.

[21]. Medrado AP, Soares AP, Santos ET, Reis SR, Andrade ZA. Influence of laser photobiomodulation upon connective tissue remodeling during wound healing. Journal Photochemistry Photobiology B, Biology. 2008;92:144-152.

[22]. Pereira MC, de Pinho CB, Medrado AR, Andrade Zde A, Reis SR. Influence of $670 \mathrm{~nm}$ low-level laser therapy on mast cells and vascular response of cutaneous injuries. Journal Photochemistry Photobiology B, Biology. 2010;98:188-192.

[23]. Hass HL. Therapeutic potentials of the Bioptron light: treatment of disorders in wound healing. Krankepfl Journal. 1998;36:451-3.

[24]. Lee BH, Kim HO, Han H J, Houh, W. Phototherapy of acne vulgaris with low level narrow band red light $(680 \mathrm{~nm})$. Korean Journal of Dermatology. 2004;42:1566-1573.

[25]. Fenyo M, Mandl J, Falus A. Opposite effect of linearly polarized light on biosynthesis of interleukin6 in a human B lymphoid cell line and peripheral human monocytes. Cell Biology International. 2002;26:265-269.

How to cite this article:

Hany M. I. Elgohary, Hadaya M. R. Eladl, Ibrahim E. Abdelzaher . POLARIZED

LIGHT: A CONSERVATIVE THERAPEUTIC APPROACH TO CHRONIC HAND

ECZEMA . Int J Physiother Res 2017;5(3):2113-2118. DOI: 10.16965/ ijpr.2017.154 